\title{
Assessment of the possibility of improving the efficiency of the organizational and technological model of the building under construction through the use of foreign single estimated standards for construction works
}

\author{
Rustam Fatullaev ${ }^{1 *}$, Veronika Gergaulova ${ }^{2}$ and Stanislav Aydarov ${ }^{3}$ \\ ${ }^{1}$ Moscow State University of Civil Engineering, Moscow, 129337, Russia \\ ${ }^{2}$ National Research University Higher School of Economics (HSE University), 101000, Moscow, \\ Russia \\ ${ }^{3}$ OOO "BidovGrupp", 125009, Moscow, Russia
}

\begin{abstract}
The influence of project management in construction industry has been increased significantly in recent years due to development of various management tools, such as BIM for instance. Nevertheless, all technological innovations and developments are based on a fundamental knowledge and skills in this area, such as: correct scope, time, cost and quality management. The previously mentioned skills are widely known, described in detail and employed in a varying degree all over the world. However, the results of project planning that have been achieved, albeit in the exact same manor may vary greatly throughout the world due to parameters in standard databases in different countries, such as activity costs, established workforce performance and formation of the crews. The task of this research is to develop an economical, cost and time planning for the execution of construction for the residential estate, according to the fundamental management tools based on the Russian and Spanish standard databases, in order to examine the distinct differences between said databases.
\end{abstract}

\section{Introduction}

The aim of this thesis is to base on the fundamental knowledge of project management, that has been achieved during the degree in Civil and Industrial Construction and master course in Structural and Construction Engineering, develop the initial economical, time and cost planning for one project based upon corresponding Russian and Spanish databases. Having obtained this information, it would be possible to compare the results and describe both the similarities and differences between them.

For this purpose, the residential estate has been chosen as the project in question. It is a modern complex that is currently under execution in Moscow. This project was developed

\footnotetext{
*Corresponding author: FatullaevRS@mgsu.ru
} 
by a foreign company in Russia and has been chosen out of various options for this study due to considerable number of international material suppliers who are involved in this project. This factor allows the omission of the depth analysis of some elements and material quality which, in the author's opinion, allows for more accurate results.

\section{Methods}

This article places emphasis on one general factor of project management: work force which is related throughout any project. The sequence of research is:

- Analysis of Russian and Spanish standards in order to find the way to exchange each other. As there is a vast difference in prices, particularly in regards to geographical location within the country, especially in Russia, it has been decided to research standards for Moscow and Barcelona;

- Activities definition and work force performance in agreement with the norms of two different countries;

- Concluding task is to compare the achieved results and submit conclusions.

\section{Resuits}

One the most important parameter in organisational model are work force. According to Moscow there are several databases for cost determination, such as Federal unit Rates, Territorial unit Rates, Regional estimated standards and Moscow territorial costing standards. The Regional estimated standards have been chosen as the database for this study. [2] For this study only two chapters have been used: "Average estimated prices for materials, products and structures" and chapter 3 "Construction works" from Regional estimated standards.This database was put into use from the 1st of December 2006. It contains information for construction, repairing and restoration works. The costs for each activity, such as payment of labour per employee, prices for material and technical resources are considered as of the 1st of January 2000. Since then, the information is updated monthly with the conversion factors for every activity to maintain actual prices.It is possible to provide an example to clarify this procedure. For instance, the direct costs of a substructure's wall concreting with thickness $250 \mathrm{~mm}$ and a cumulative volume of $150 \mathrm{~m} 3$ should be calculated.

Ability to use standards

During the research, a number of technological processes were selected. The main criteria for choosing technological solutions were: the technological process should be widely applicable in practice; the technological process should be present simultaneously in the standards of Russia and Spain, etc.

Works that meet the selected search parameters are shown below:

- $\quad$ Concreting the Foundation plate with a concrete pump;

- $\quad$ Reinforcement of the Foundation plate with individual rods;

- $\quad$ Arrangement of underlying and leveling layers of bases;

- $\quad$ Reinforcement of walls

Under the Russian standards, the standard value of the complexity of any work is determined by multiplying the amount of work on the normative labor costs of units of work according to gesn, building code or other regulatory documents.

Planned value labor of any work is determined by multiplying the amount of relevant work on the planned labor units for this work. Moreover, the planned labor intensity is 
calculated based on the standard labor intensity, taking into account the introduction of organizational and technological measures that reduce the cost of working time.

According to Moscow, there are several databases for determining costs, such as Federal unit rates, territorial unit rates, regional estimates, and Moscow territorial estimates. Regional assessment standards were selected as the database for this study. Only two chapters were used for this study: average estimated prices for materials, products and structures, and Chapter 3 construction works from regional estimated standards. This database was put into operation on December 1, 2006. It contains information about construction, repair and restoration work.

Data from Russian and Spain standards for selected works are presented in the tables below:

Table 1. Concreting the Foundation plate with a concrete pump (m3) Russia

\begin{tabular}{llc}
\hline Human and technical resources & Unit & Value \\
\hline Labor costs of workers & Man-hour & 0.6113 \\
Rotary-hose concrete pumps, capacity up to & Tech-hour & 0.1114 \\
$60 \mathrm{~m} 3 / \mathrm{h}$, height up to $30 \mathrm{~m}$ & & 0.0847 \\
Vibrators for sale & Tech-hour & 0 \\
\hline
\end{tabular}

Table 2.Reinforcement of the Foundation plate with individual rods ( $t$ ) Russia

\begin{tabular}{llr}
\hline Human and technical resources & Unit & Value \\
\hline Labor costs of workers & Man-hour & 21.73 \\
Cranes on the road, carrying capacity up to 16 t & Tech-hour & 0.11 \\
\hline
\end{tabular}

Table 3. Arrangement of the underlying and leveling layers (m3) Russia

\begin{tabular}{llc}
\hline Human and technical resources & Unit & Value \\
\hline Labor costs of workers & Man-hour & 21.6 \\
Crawler bulldozers, power up to 59 kW (80 HP) & Tech-hour & 2.35 \\
Self-propelled vibratory rollers, weight up to 8 t & Tech-hour & 7.17 \\
Self-propelled vibratory rollers, weight up to 14 t & Tech-hour & 14.6 \\
Self-propelled road rollers with pneumatic wheels, & Tech-hour & 0.52 \\
weight up to 16 t & & \\
Washing machines, tank capacity up to 8 m3 & Tech-hour & 0.91 \\
Motor graders, power 99-147 kW (130-200 HP) & Tech-hour & 1.79 \\
\cline { 2 - 3 }
\end{tabular}

Table 4. Reinforcement of the walls ( $t$ ) Russia

\begin{tabular}{llr}
\hline Human and technical resources & Unit & Value \\
\hline Labor costs of workers & Man-hour & 25.23 \\
Cranes on the road, carrying capacity up to $16 \mathrm{t}$ & Tech-hour & 0.12 \\
\hline
\end{tabular}

Table 5. Concreting the Foundation plate with a concrete pump $\left(\mathrm{m}^{3}\right)$ Spain

\begin{tabular}{llc} 
Human and technical resources & Unit & Value \\
\hline Bricklayer class 1A & Man-hour & 0.096 \\
Worker & Man-hour & 0.144 \\
Concrete pump & Tech-hour & 0.08 \\
\hline
\end{tabular}

Table 6. Reinforcement of the Foundation plate with individual rods (t) Spain

\begin{tabular}{llc}
\hline Human and technical resources & Unit & Value \\
\hline Rebar 1A category & Man-hour & 6 \\
Assistant steel fixer & Man-hour & 10 \\
\hline
\end{tabular}

Table 7. Arrangement of the underlying and leveling layers (m3) Spain

\begin{tabular}{llc}
\hline Human and technical resources & Unit & Value \\
\hline Worker & Man-hour & 0.06 \\
\hline
\end{tabular}




\begin{tabular}{lll}
\hline Small grader & Tech-hour & 0.035 \\
Self-propelled vibrating roller from 12 to $14 \mathrm{t}$ & Tech-hour & 0.03 \\
$8 \mathrm{~m} 3$ tank truck & Tech-hour & 0.025 \\
\hline
\end{tabular}

Table 8. Reinforcement of the walls (t) Russia

\begin{tabular}{llc}
\hline Human and technical resources & Unit & Value \\
\hline Rebar 1A category & Man-hour & 10 \\
Assistant steel fixer & Man-hour & 12 \\
\hline
\end{tabular}

Let's bring all the standards to a single unit of measurement

Determine the elaborate for each type of work per unit of measurement:

Table 9. Summary table of elaborate for all types of workfor two countries

\begin{tabular}{|c|c|c|c|}
\hline Name of work & Unit & $\begin{array}{l}\text { Elaborate } \\
\text { (Russia) }\end{array}$ & $\begin{array}{l}\text { Elaborate } \\
\text { (Spain) }\end{array}$ \\
\hline $\begin{array}{l}\text { Concreting the Foundation plate with a } \\
\text { concrete pump }\end{array}$ & $1 \mathrm{~m} 3$ & 0.122 & 0.048 \\
\hline $\begin{array}{l}\text { Reinforcement of the Foundation plate } \\
\text { with individual rods }\end{array}$ & $1 \mathrm{t}$ & 2.71 & 2 \\
\hline $\begin{array}{l}\text { Arrangement of underlying and leveling } \\
\text { layers of bases }\end{array}$ & $1 \mathrm{~m} 3$ & 21.6 & 0.06 \\
\hline Reinforcement of walls & $1 \mathrm{t}$ & 2.29 & 2 \\
\hline
\end{tabular}

The equation of the pair regression.

Using the graphical method.

This method is used to visualize the form of communication between the studied economic indicators. To do this, in a rectangular coordinate system build the graph, the ordinate of the lay individual values of resultant variable $\mathrm{Y}$, and the abscissa shows the individual values of factor $\mathrm{X}$.

The set of points of effective and factor features is called the correlation field.

Based on the correlation field, we can hypothesize (for the General population) that the relationship between all possible values of $\mathrm{X}$ and $\mathrm{Y}$ is linear.

The linear regression equation has the form $y=b x+a$

The estimated regression equation (constructed from sample data) will have the form y $=\mathrm{bx}+\mathrm{a}+\varepsilon$, where ei are the observed values (estimates) of errors ei, a and b, respectively, estimates of the parameters $\alpha$ and $\beta$ of the regression model to be found.

Here $\varepsilon$ is a random error (deviation, perturbation).

Reasons for the existence of a random error:

1. non-Inclusion of significant explanatory variables in the regression model;

2. Aggregation of variables. For example, the total consumption function is an attempt to generalize the totality of individual spending decisions. This is only an approximation of individual relations that have different parameters.

3. Incorrect description of the model structure;

4. Incorrect functional specification;

5. The error of measurement.

Since the deviations of ei for each particular observation are I-random and their values in the sample are unknown, then:

1) only estimates of the parameters $\alpha$ and $\beta$ can be obtained from observations xi and yi

2) Estimates of the parameters $\alpha$ and $\beta$ of the regression model are, respectively, values $\mathrm{a}$ and $\mathrm{b}$, which are random in nature, since they correspond to a random sample;

To estimate the parameters $\alpha$ and $\beta$ - use OLS (least squares method). 
The least squares method gives the best (consistent, efficient, and unbiased) estimates of the parameters of the regression equation. But only if certain assumptions about the random term $(\varepsilon)$ and the independent variable $(\mathrm{x})$ are met.

Formally, the OLS criterion can be written as follows:

$$
\mathrm{S}=\sum(\mathrm{yi}-\mathrm{y} * \mathrm{i}) 2 \rightarrow \min
$$

System of normal equations.

$$
\begin{gathered}
a \cdot n+b \cdot \sum x=\sum y \\
a \cdot \sum x+b \cdot \sum x 2=\sum y \cdot x
\end{gathered}
$$

To calculate the regression parameters, we will build a calculation table (table 10)

Table 10.Regression parameters

\begin{tabular}{llcll}
\hline $\mathrm{x}$ & $\mathrm{y}$ & $\mathrm{x}^{2}$ & $\mathrm{y}^{2}$ & $\mathrm{x}^{*} \mathrm{y}$ \\
\hline 0.122 & 0.048 & 0.01488 & 0.0023 & 0.00586 \\
2.71 & 2 & 7.3441 & 4 & 5.42 \\
21.6 & 0.06 & 466.56 & 0.0036 & 1.296 \\
2.29 & 2 & 5.2441 & 4 & 4.58 \\
26.722 & 4.108 & 479.1631 & 8.0059 & 11.3019 \\
\hline
\end{tabular}

For our data, the system of equations has the form

$4 \mathrm{a}+26.722 \cdot \mathrm{b}=4.108$

$26.722 \cdot \mathrm{a}+479.163 \cdot \mathrm{b}=11.302$

Multiply the equation (1) of the system by (-6.681), we get a system that we solve by algebraic addition.

$$
\begin{gathered}
-26.722 a-178.53 b=-27.446 \\
26.722 * a+479.163 * b=11.302
\end{gathered}
$$

Receive:

$300.633 * b=-16.144$

From where $b=-0.05369$

Now find the coefficient "a" from equation (1):

$4 \mathrm{a}+26.722 * \mathrm{~b}=4.108$

$4 \mathrm{a}+26.722 *(-0.05369)=4.108$

$4 \mathrm{a}=5.543$

$\mathrm{a}=1.3857$

We get empirical regression coefficients: $b=-0.05369, a=1.3857$

The regression equation (an empirical equation of regression):

$\mathrm{y}=-0.05369 \mathrm{x}+1.3857$

The empirical regression coefficients $a$ and $b$ are only estimates of the theoretical coefficients $\beta \mathrm{i}$, and the equation itself reflects only the General trend in the behavior of the variables under consideration.

The linear regression equation has the form $y=-0.0537 \mathrm{x}+1.386$

The coefficients of the linear regression equation can be given an economic meaning.

The regression coefficient $b=-0.0537$ shows the average change in the effective indicator (in units of y) with an increase or decrease in the value of the factor $x$ per unit of its measurement. In this example, with an increase of 1 unit, y decreases by an average of 0.0537 .

The coefficient $\mathrm{a}=1.386$ formally shows the predicted level of $\mathrm{y}$, but only if $\mathrm{x}=0$ is close to the sample values. 
But if $\mathrm{x}=0$ is far from the sample values of $\mathrm{x}$, then a literal interpretation can lead to incorrect results, and even if the regression line describes the values of the observed sample fairly accurately, there is no guarantee that it will also be when extrapolating to the left or right.

By substituting the corresponding values of $\mathrm{x}$ into the regression equation, you can determine the aligned (predicted) values of the resultant $\mathrm{y}(\mathrm{x})$ for each observation.

The relationship between $\mathrm{y}$ and $\mathrm{x}$ determines the sign of the regression coefficient $\mathrm{b}$ (if $>0$ - direct relationship, otherwise - reverse). In our example, the relationship is reversed.

2. Estimation of parameters of the regression equation.

The dependence of $\mathrm{Y}$ on $\mathrm{x}$ is studied. At the specification stage, a paired linear regression was selected. Its parameters are estimated using the least squares method. An economic interpretation of the model parameters is possible: an increase in $\mathrm{X}$ by 1 unit of change leads to a decrease in $\mathrm{Y}$ by an average of 0.0537 units of change.

\section{Conclusions}

The results of the study show that there is a correlation between the studied parameters. This suggests that it is possible to use the pair correlation coefficient to borrow individual country maps from different countries.

\section{References}

1. A. Lapidus, I. Abramov, Science and Business 10, 17-28 (2017)

2. A.A. Lapidus, A.N. Makarov, Bulletin of Moscow State University of Civil Engineering 8, 150-160 (2015)

3. A.O. Khubaev, Prospects of science 4 (103), 57-61 (2018)

4. V.Y. Mishchenko, D.I, Yemelyanov, A.A. Tikhonenko, Industrial and Civil Engineering 10, 69-71 (2013)

5. R.S. Fatullaev, Components of Scientific and Technological Progress 3(33), 17-22 (2017)

6. A. Khubaev, T. Bidov, A. Bzhienikov, V. Nesterova, IOP Conf. Series: Materials Science and Engineering 365, 81-96(2018)

7. A. Lapidus, T. Bidov, A. Khubaev, MATEC Web of Conferences 117, (2017)

8. Topchiy D.V., Shatrova A.I.International Journal of Mechanical Engineering and Technology 4, 539-547 (2018)

9. M. Liu, G. Ballard, Proceedings for the 16th Annual Conference of the International Group for Lean Construction, Planning and Control 1, 657-666 (2008)

10. L. Floreza, J.C. Cortissoz, Procedia Engineering 164, 42 - 48 (2016)

11. A.A. FardFini, T.H. Rashidi, Journal of Construction Engineering and Management 1, 28-41 (2016)

12. Khubaev A., Bidov T., Rybakova A., MATEC Web of Conferences 27th R-S-P Seminar, Theoretical Foundation of Civil Engineering (27RSP), TFoCE 27, 04071 (2018)

13. Lapidus A.A., Govorukha P.A.International Journal of Applied Engineering Research 20, 40946-40949 (2015) 
14. Topchiy D., Tokarskiy A., IOP Conference Series: Materials Science and Engineering 21, Construction - The Formation of Living Environment, 062005 (2018)

15. Abramov I.L., Lapidus A.A., Construction - The Formation of Living Environment conference proceedings, 062002 (2018)

16. Topchiy D., Skakalau V., A. Yurgaytis, International Journal of Civil Engineering and Technology 1, 985-993 (2018) 